FERDINANDO CESAR LUNARDI FILHO

A REMUNERAÇÃO DOS ADMINISTRADORES DAS SOCIEDADES ANÔNIMAS

\author{
Dissertação de Mestrado
}

Orientador: Prof. Doutor Eduardo Secchi Munhoz

Faculdade de Direito da Universidade de São Paulo

São Paulo

2013 


\section{A REMUNERAÇÃO DOS ADMINISTRADORES DAS SOCIEDADES ANÔNIMAS}

Dissertação apresentada à Faculdade de Direito da Universidade de São Paulo, sob orientação do Prof. Doutor Eduardo Secchi Munhoz, como requisito para a obtenção do grau de mestre em direito.

Candidato: Ferdinando Cesar Lunardi Filho

Faculdade de Direito da Universidade de São Paulo

São Paulo

2013 


\section{Banca Examinadora}

Orientador:

Professor:

Professor: 


\section{Resumo}

Este trabalho examina a disciplina legal da remuneração dos administradores das sociedades anônimas. A análise é feita a partir de três perspectivas: (i) a dos incentivos que as estruturas de remuneração podem gerar ao desempenho dos administradores; (ii) a dos problemas e conflitos que a remuneração pode causar, notadamente entre os acionistas controladores e os não controladores, bem como entre os administradores e os acionistas; e (iii) a das soluções que a remuneração proporciona, sobretudo ao alinhar os interesses dos administradores com os da companhia e dos acionistas. Entre os objetivos esperados estão a contribuição para as discussões teóricas sobre a remuneração dos administradores e o aperfeiçoamento da aplicação da sua disciplina legal. Para tanto, serão de especial importância os comentários sobre a necessidade de aprimoramento das práticas de governança corporativa, em particular (i) a transparência, como mitigador de assimetria informacional e indutor de comportamentos adequados; e (ii) o comitê de remuneração, como elemento agregador de independência e redutor dos conflitos de interesse. Do ponto de vista estrutural, o trabalho divide-se em 6 capítulos. O primeiro contextualiza a importância da discussão teórica sobre o tema à luz de três recentes eventos: (i) a edição da Instrução CVM nº 480, de 2009; (ii) o crescimento do mercado de capitais brasileiro; e (iii) a dispersão da propriedade acionária observada em algumas companhias e a relação entre essa dispersão e a remuneração dos administradores. O segundo capítulo faz uma incursão na discussão sobre a remuneração dos administradores nos Estados Unidos, tratando dos problemas de agência e da remuneração como solução parcial para os referidos problemas ou parte integrante deles. O terceiro capítulo cuida da disciplina da remuneração dos administradores na Lei $\mathrm{n}^{\circ}$ 6.404, de 1976. Os capítulos 4 e 5 tratam de modo específico de duas das modalidades de remuneração historicamente mais importantes nas companhias brasileiras: a participação nos lucros e a remuneração baseada em ações, particularmente as opções de compra de ações. Por fim, o sexto capítulo fecha o trabalho com considerações finais sobre a análise realizada e sobre as reflexões e estudos ainda a serem conduzidos.

Palavras-chave: sociedade anônima; problemas de agência; alinhamento de interesses; remuneração dos administradores; participação nos lucros; opções de compra de ações; governança corporativa; transparência; comitê de remuneração. 


\begin{abstract}
The aim of this study is to examine the legal framework of executive compensation in Brazilian corporations. The analysis is conducted from three perspectives: (i) the incentives that compensation structures can create towards the enhancement of executives' performance; (ii) the problems and conflicts arising from compensation schemes, particularly between controlling and non-controlling shareholders, as well as between managers and shareholders in general; and (iii) the solutions provided by compensation schemes, especially by aligning the interests of managers with those of the company and its shareholders. Some of its intended objectives are contributing to theoretical discussions about executive compensation and improving the application of its legal framework. For these purposes, comments on the need for improvement of corporate governance practices are noteworthy, particularly when it comes to: (i) disclosure, as a measure capable of mitigating information asymmetry and inducing appropriate behavior; and (ii) the compensation committee, as an element capable of promoting independence and reducing conflicts of interest. In terms of structure, this study is divided into six (6) chapters. The first chapter contextualizes the importance of theoretical discussion on the topic, taking into account three recent events: (i) the issue of CVM Instruction No. 480, of 2009, by the Brazilian Securities and Exchange Commission; (ii) the growth of the Brazilian capital market; and (iii) the ongoing shareholding dispersion noticed in some companies and the relationship between such dispersion and executive pay. The second chapter tours the discussion about executive compensation in the United States, dealing with agency problems and with compensation schemes as either part of such problems or a partial remedy to them. The third chapter addresses the legal framework of executive compensation as established by Law No. 6,404, of 1976. Chapters 4 and 5 encompass two specific compensation schemes among the most historically important ones for Brazilian companies: profit sharing and equity-based compensation, particularly stock options. At last, Chapter 6 concludes this study with final remarks on the analysis conducted herein and on the reflections and studies to be yet carried out.
\end{abstract}

Keywords: corporation; agency problems; aligning of interests; executive compensation; profit sharing; stock options; corporate governance; disclosure; compensation committee. 


\section{Sumário}

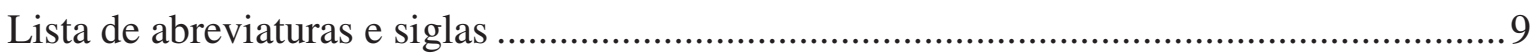

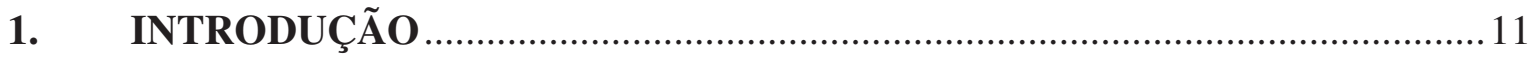

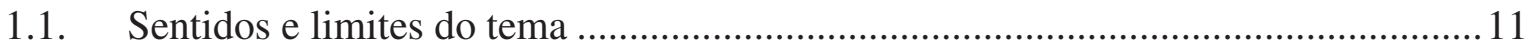

1.2. Plano da exposição e divisão do trabalho ............................................................ 15

2. SOCIEDADE ANÔNIMA, ALINHAMENTO DE INTERESSES E REMUNERAÇÃO DOS ADMINISTRADORES .......................................... 19

2.1. Panorama da discussão sobre remuneração dos administradores nos Estados Unidos 19

2.2. A sociedade anônima, a tendência natural e permanente ao desalinhamento de

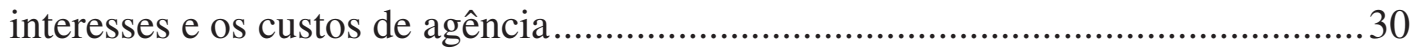

2.3. A remuneração dos administradores e os custos de agência: problema ou solução parcial?

2.3.1. Remuneração como solução parcial para os problemas de agência (optimal contract approach)

2.3.2. Remuneração dos administradores como parte integrante dos problemas de agência (managerial power approach)..................................................... 38

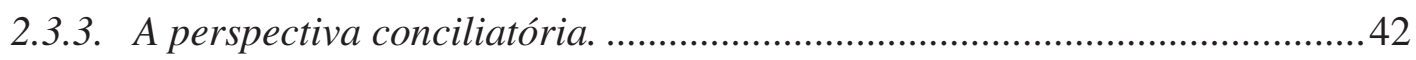

2.4. A relação entre dispersão acionária e a remuneração dos administradores: novos desafios.

2.5. Objetivos concretos e composição da remuneração ............................................. 49

3. A REMUNERAÇÃO DOS ADMINISTRADORES DE SOCIEDADES ANÔNIMAS NA LEI No 6.404, DE 1976 ..................................................... 51

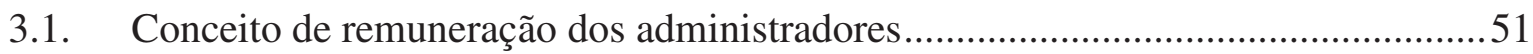

3.2. Evolução histórica da disciplina da remuneração dos administradores....................55

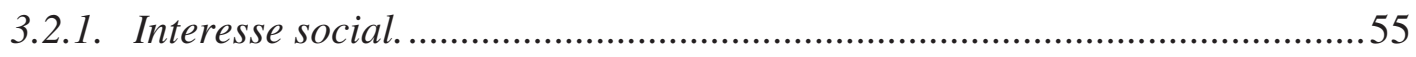

3.2.2. Remuneração dos administradores.........................................................59

3.3. Tipos de remuneração dos administradores na Lei $\mathrm{n}^{\circ}$ 6.404, de 1976 .....................68

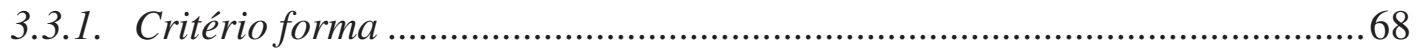

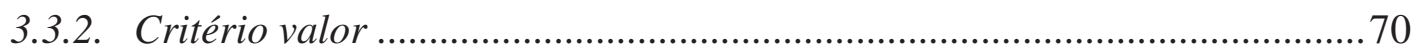

3.4. Art. 152, caput, da Lei $\mathrm{n}^{\circ}$ 6.404, de 1976: fixação da remuneração dos

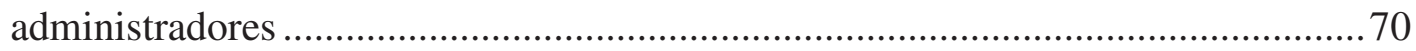


3.4.1. Competência para fixação da remuneração

3.4.2. Procedimento para fixação da remuneração ............................................. 77

3.4.3. Benefícios de qualquer natureza e verbas de representação. .......................78

3.4.4. Critérios e parâmetros para a fixação da remuneração .............................. 81

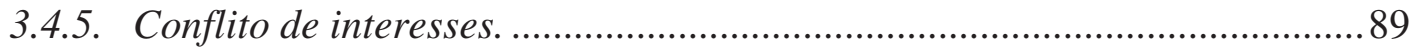

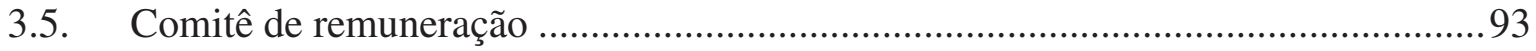

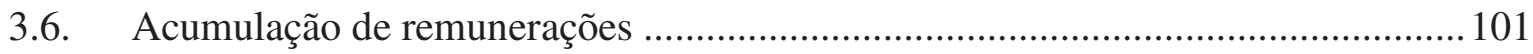

3.7. Renúncia ao cargo ou destituição do administrador ............................................. 102

3.8. Benefícios pós-emprego e motivados pela cessação do exercício do cargo (golden parachutes) 105

3.9. Art. $157, \S 1^{\circ}$, d, da Lei $\mathrm{n}^{\circ}$ 6.404, de 1976: revelação das condições dos contratos de

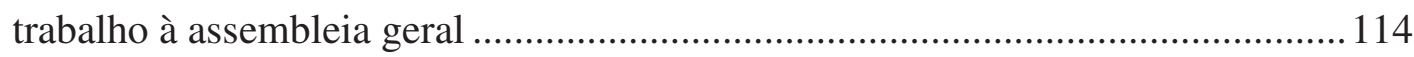

3.10. Remuneração dos membros do conselho fiscal. .................................................. 115

3.11. Não pagamento pela companhia da remuneração fixada em assembleia ..............117

3.12. Remuneração dos administradores nos grupos societários .................................... 118

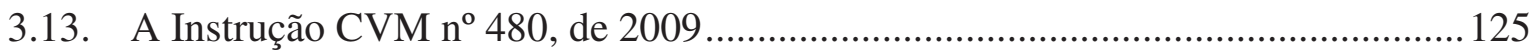

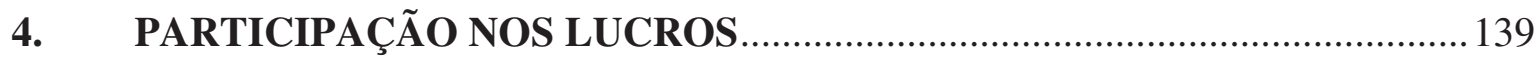

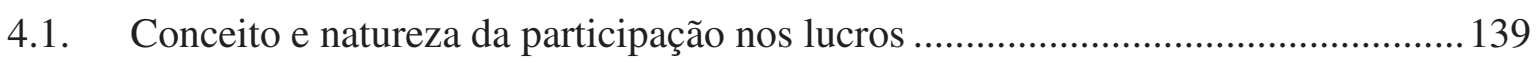

4.2. Participação nos lucros e a percepção de risco pelos administradores ................... 142

4.3. Participação nos lucros e lógica econômica........................................................... 144

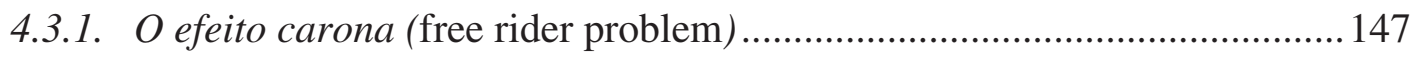

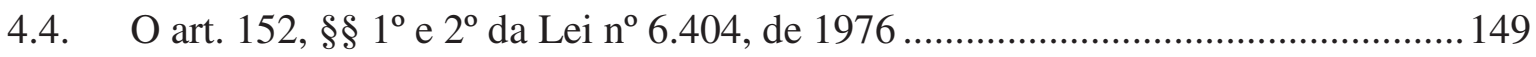

4.5. Limitações para as participações nos lucros .......................................................... 153

4.6. Participação estatutária e/ou extraestatutária ....................................................... 156

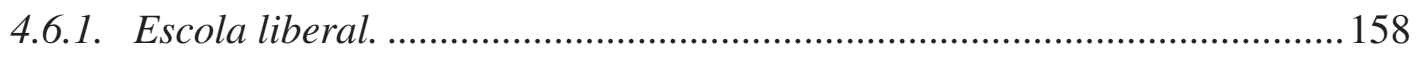

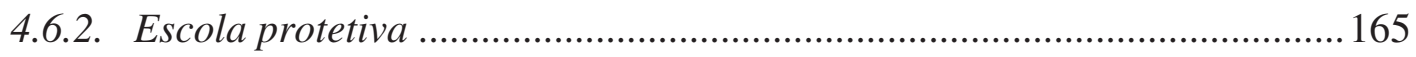

4.6.3. Finalidades e consequências da discussão. ............................................... 171

4.7. Art. 189 e art. 190 da Lei $n^{\circ}$ 6.404, de 1976: base para o cálculo da participação 173

4.8. Pagamento da participação nos lucros aos administradores: necessidade de prévia distribuição de dividendos e existência de lucros ................................................ 177

4.9. Os parágrafos do art. 201 da Lei $\mathrm{n}^{\circ}$ 6.404, de 1976: a responsabilidade dos

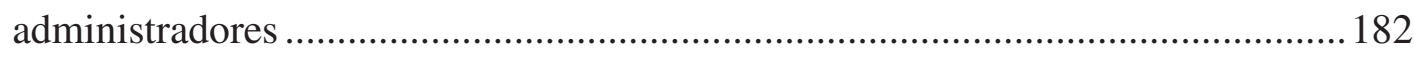

4.10. Participação com base em lucros intermediários ............................................... 185

4.11. Renúncia ou destituição do administrador e participação nos lucros. .................... 192 
4.12. Art. 294, $\S 2^{\circ}$ da Lei ${ }^{\circ}$ 6.404, de 1976: companhias com até 20 acionistas 193

4.13. Art. 274 da Lei 6.404, de 1976: participação nos lucros e grupos societários

4.14. A Instrução CVM n ${ }^{\circ} 480$, de 2009

5. REMUNERAÇÃO DOS ADMINISTRADORES BASEADA EM AÇÕES ...200

5.1. Conceito, natureza e objetivo das opções de compra de ações 202

5.2. Funcionamento das opções de compra de ações 205

5.2.1. Requisitos para implementação. Art. 168, $\S^{\circ}$, da Lei $n^{\circ} 6.404$, de 1976..206

5.2.2. Formas pelas quais a companhia compõe o conjunto de ações a serem atribuídas aos administradores: aumento de capital ou recompra de ações

5.2.3. Exclusão do direito de preferência: art. 171, §3º, da Lei $n^{\circ} 6.404$, de 1976 209

5.2.4. Prazo de carência (vesting period). 210

5.2.5. Exercício e preço de exercício das opções 212

5.3. A questão terminológica: "opção de compra de ações" vs. "opção de subscrição de ações" 218

5.4. Diferenças entre opção de compra de ações e bônus de subscrição 219

5.5. Cessibilidade vs. caráter intuitu personae das opções. 222

5.6. Planos de ações restritas (restricted stock/shares)..............................................224

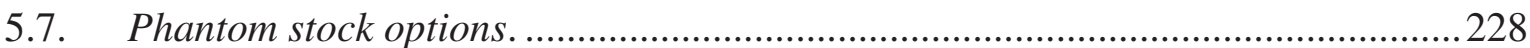

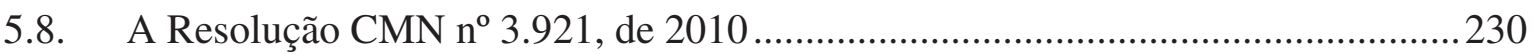

5.9. As opções de compra e os grupos societários.........................................................235

5.10. As opções de compra de ações e eventuais comportamentos oportunísticos ........239

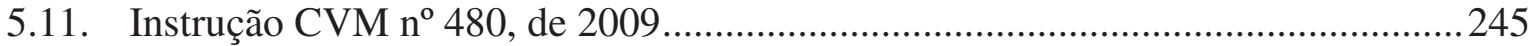

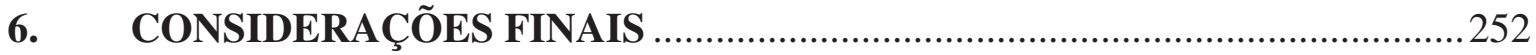

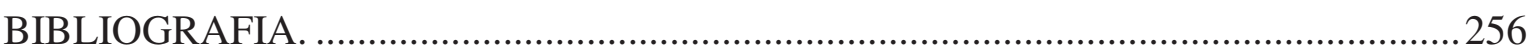




\section{Lista de abreviaturas e siglas}

ABDI

Ag. Reg.

CAA

CEO

$\mathrm{CFO}$

CVM

CMN

FSB

IBEF

IBGC

IBRACON

IFRS

$\mathrm{MC}$

NADC

NASDAQ

NBER

NYSE

PFE

PIB

RDM

REsp.

Rel.

RT

SDM

SEC

SEP

SL

STF

STJ

TAMG

TJPR
Agência Brasileira de Desenvolvimento Industrial

Agravo Regimental

Creative Artists Agency

Chief Executive Officer

Chief Financial Officer

Comissão de Valores Mobiliários

Conselho Monetário Nacional

Financial Stability Board

Instituto Brasileiro de Executivos de Finanças

Instituto Brasileiro de Governança Corporativa

Instituto Brasileiro de Contabilidade

International Financial Reporting Standards

Medida Cautelar

National Association of Corporate Directors

National Association of Securities Dealers Automated Quotations

National Bureau of Economic Research

New York Stock Exchange

Procuradoria Federal Especializada da CVM

Produto Interno Bruto

Revista de Direito Mercantil, Industrial, Econômico e Financeiro

Recurso Especial

Relator

Revista dos Tribunais

Superintendência de Desenvolvimento de Mercado da CVM

Securities and Exchange Commission

Superintendência de Relações com Empresas da CVM

Suspensão de Liminar

Supremo Tribunal Federal

Superior Tribunal de Justiça

Tribunal de Alçada de Minas Gerais

Tribunal de Justiça do Estado do Paraná 
TJRJ

TJSC

TJSP

TRF2

Tribunal de Justiça do Estado do Rio de Janeiro

Tribunal de Justiça do Estado de Santa Catarina

Tribunal de Justiça do Estado de São Paulo

Tribunal Regional Federal da $2^{\mathrm{a}}$ Região

$* * *$ 


\section{INTRODUÇÃo}

\subsection{Sentidos e limites do tema}

A remuneração dos administradores das sociedades anônimas é um tema muito caro ao direito societário. Compreender bem os incentivos que a remuneração pode gerar aos administradores, enquanto depositários da confiança dos acionistas e sujeitos aos seus deveres fiduciários, é essencial. Tais incentivos geram sérias repercussões na esfera de interesses da sociedade, seus acionistas e seus administradores, o que pode impactar positiva ou negativamente a relação entre esses agentes. Não estranha, então, que, há muito tempo, a doutrina cuide do assunto como um tema de fundamental importância. ${ }^{1}$

Nos últimos anos, porém, a remuneração dos administradores tem assumido papel ainda mais central por, pelo menos, três razões: (i) a edição, pela Comissão de Valores Mobiliários ("CVM"), da Instrução CVM n ${ }^{\circ} 480$, de 2009, que passou a exigir a divulgação de informações sobre a remuneração dos administradores de companhias abertas; (ii) o crescimento vivenciado pelo mercado de capitais brasileiro, especialmente na última década; e (iii) o aumento da dispersão acionária de algumas companhias brasileiras, gerando impactos na estrutura de remuneração dos administradores dessas companhias.

Em primeiro lugar, o ambiente regulatório sofreu uma modificação importante com a edição da Instrução CVM no 480, de 2009. O referido documento representou uma mudança de paradigma em relação às exigências de transparência até então impostas pelo órgão regulador às companhias abertas. De um lado, nunca antes as companhias tiveram que divulgar informações com tanta clareza e transparência. De outro, por conseguinte, os investidores e profissionais do mercado de capitais nunca tiveram acesso a tamanha disponibilidade de dados relativos às companhias.

\footnotetext{
${ }^{1}$ Cf. J. X. CARVAlho de Mendonça, Tratado de direito comercial brasileiro, v. 4, 6 ${ }^{\text {a }}$ Ed., Rio de Janeiro, Freitas Bastos, 1959, p. 48; T. M. VALVERDE, Sociedades por ações, v. 2, Rio de Janeiro, Forense, 1941, p. 20; G. PIRES, Manual das Sociedades Anônimas, Rio de Janeiro, Freitas Bastos, 1942, pp. 253/254; R. C. GuIMARÃES, Sociedade por Ações, v. 2, Rio de Janeiro, 1960, pp. 183/188; e W. FERREIRA, Abuso de direito das assembleias gerais no fixarem os subsídios dos diretores das sociedades anônimas, in Revista de Direito Mercantil, v. II, 1952, pp. 528/553.
} 
Especificamente quanto à remuneração dos administradores das companhias abertas, a Instrução CVM n ${ }^{\circ}$ 480, de 2009, estabelece uma rígida política de divulgação de informações. Há, no referido documento, uma seção específica inteiramente dedicada à remuneração dos administradores. Essas novas exigências de disclosure geram efeitos importantes tanto na esfera de interesse dos investidores quanto na da companhia.

Do ponto de vista dos investidores, a disponibilidade dessas informações possibilita identificar com clareza os custos incorridos pela companhia com sua administração. Ademais, a divulgação de tais informações permite aos investidores não apenas saber o montante global gasto com a gestão da companhia, mas também as estruturas e métricas utilizadas, o regime de incentivos a que estão sujeitos os administradores e como os interesses podem ser alinhados.

Do ponto de vista da companhia, espera-se que a obrigação de divulgar as políticas de remuneração tenha o efeito indutor de cumprimento de suas obrigações legais, de adoção pelas companhias das melhores práticas de governança corporativa e das políticas de remuneração dos administradores que sejam adequadas e que efetivamente alinhem os interesses dos acionistas aos da administração.

Em segundo lugar, na última década, o mercado de capitais brasileiro vivenciou um crescimento extraordinário. De acordo com informações da CVM, ao final de 2012, já havia 640 companhias registradas na CVM e 364 listadas na Bolsa de Valores. Ainda de acordo com tais informações, em 2002, o volume de recursos captados via oferta de valores mobiliários somava o montante de $\mathrm{R} \$ 25.458 .000,00$, dos quais $\mathrm{R} \$ 6.667 .000,00$ representavam o volume de recursos captados via oferta de ações. Em 2012, esses números montavam $\mathrm{R} \$ 141.862 .000,00$, e $\mathrm{R} \$ 11.381 .000,00$, respectivamente. Por fim, o valor de mercado das companhias, que em 2002 era $\mathrm{R} \$ 438.000 .000,00$, em 2012 saltou para $\mathrm{R} \$ 2.415 .318 .000,00$, ou seja, foi multiplicado por 5 vezes.

Essa evolução do mercado tem impactos muito claros na discussão da remuneração dos administradores de companhias. O maior número de investidores que passam a alocar parcelas de seus patrimônios em ações de companhias abertas, o aumento do número de companhias que passam a acessar o mercado de capitais como uma via eficiente de 
financiar o incremento de seus projetos, e o consequente aumento do volume de recursos movimentados no mercado apontam para uma maior preocupação com os custos incorridos pelas companhias, e, sobretudo, com a remuneração dos gestores desses empreendimentos. Mas duas vertentes desse crescimento são especialmente importantes.

A primeira consiste no recente desenvolvimento do mercado de private equity e venture capital. A indústria latino americana de private equity tem se tornado mais representativa, especialmente a brasileira. Em 2011, fundos de private equity captaram um total de US\$10.13 bilhões para investir em empreendimentos na América Latina. O Brasil foi o líder da região, recebendo cerca de US\$8.1 bilhões, valor que representou $80 \%$ do total destinado a investimentos na América Latina nesse período. Os investimentos em private equity e venture capital no Brasil já representam 0,27\% do seu PIB. ${ }^{2}$

$\mathrm{O}$ crescimento da indústria de private equity e venture capital tem muitas externalidades positivas. Fundos de private equity procuram gerar valor por meio da profissionalização da gestão e da adoção das melhores práticas de governança corporativa. Um dos principais impactos do crescimento da indústria de private equity, dessa forma, é a apresentação ao mercado de companhias com gestões profissionalizadas e com práticas diferenciadas de governança e, portanto, preocupadas com os custos incorridos e com a remuneração de seus administradores. A presença de fundos de private equity e outros investidores institucionais no quadro societário das companhias tende a aumentar o monitoramento sobre as atividades da administração e reduzir a influência dos administradores sobre a definição da sua própria remuneração. ${ }^{3}$

A segunda vertente do crescimento do mercado de valores mobiliários brasileiro reside nas recentes iniciativas público-privadas para fomentar o acesso ao mercado de

2 Fonte: Latin America Private Equity \& Venture Capital Association - LAVCA, disponível em www.lavca.org. Para maiores detalhes a respeito do atual estágio de desenvolvimento da indústria brasileira de private equity, cf. AgÊNCIA BRASILEIRA DE DESENVOLVIMENTO INDUSTRIAL - ABDI, $A$ indústria de Private Equity e Venture Capital - $2^{\circ}$ Censo Brasileiro, março de 2011, disponível em www.abdi.com.br.

${ }^{3}$ Cf. L. A. Bebchuk, J. M. FrIED, Executive compensation as an Agency problem, 2003, disponível em http://papers.ssrn.com/abstract_id=364220, p. 7; e P. DAVID, R. KOCHHAR, E. LEVITAS, The effect of institutional investors on the level and mix of CEO compensation, in The Academy of Management Journal, v. 41,1998 , pp. 200/208. 
capitais por pequenas e médias empresas. ${ }^{4}$ De um lado, vêm sendo estudadas práticas de mercado, tais como o alinhamento de interesses, com o objetivo de reduzir a percepção de risco dos investidores; o desenvolvimento de uma rede de intermediação que alcança investidores; a disseminação de uma cultura de investimento e de risco, entre outras.

De outro, vêm sendo analisadas medidas que poderiam ser adotadas pelo governo brasileiro para estimular o desenvolvimento de tal mercado, tais como a criação de incentivos tributários a investidores que invistam nessas empresas; a criação de veículos de investimento específicos para esse mercado; normas específicas para facilitar o acesso ao mercado de capitais, inclusive de transparência; e auxílio financeiro às empresas para cobrir os custos associados à listagem.

Espera-se que em um futuro não muito distante existam novas companhias se beneficiando da captação de recursos via mercado de capitais. ${ }^{5}$ Essas companhias estarão obrigadas a lidar com questões de transparência, governança corporativa e relações com investidores afeitas a sociedades anônimas abertas. As políticas de remuneração dos administradores dessas companhias, por exemplo, estarão sujeitas a um nível diferenciado de disclosure, que demonstre como tais práticas alinham todos os interesses em jogo, considerando, especialmente, os interesses dos novos acionistas.

Por fim, a terceira razão consiste na dispersão acionária observada em algumas companhias brasileiras nos últimos anos. O crescimento do mercado de capitais brasileiro na última década foi acompanhado por uma mudança na própria estrutura de propriedade de algumas companhias abertas. Nos últimos anos, presenciou-se o aparecimento de companhias sem controlador definido. Existe uma tendência de intensificação desse processo, e pode ser que o número de companhias com capital pulverizado aumente nos

\footnotetext{
${ }^{4}$ A esse respeito, v. documento denominado "Utilização do Mercado de Capitais para o Financiamento de Pequenas e Médias Empresas por meio de Ações”, disponível em http://www.bmfbovespa.com.br/empresas/download/Apresentacao-Mercado-Capitais.pdf. O documento contém uma descrição dos trabalhos realizados por um comitê técnico composto por membros oriundos dos setores público e privado, bem como um diagnóstico dos problemas que deverão ser enfrentados no desenvolvimento do mercado de capitais para pequenas e médias empresas no Brasil nos próximos anos.

${ }^{5}$ Para um aprofundamento dos efeitos positivos da captação de recursos via mercado de capitais, cf. O. G. BUlHÕES, Considerações sobre o Financiamento das Empresas, in Revista Brasileira de Mercado de Capitais, v. 2, 1976, p. 503.
} 
próximos anos, tal como se observa em mercados mais desenvolvidos, como o dos Estados Unidos.

A dispersão acionária tem vários efeitos positivos, dos quais o principal talvez seja conferir maior liquidez para as ações. Mas ela também distancia os investidores dos centros decisórios da companhia, reduzindo sua capacidade de monitoramento e mesmo os incentivos para que cada investidor fiscalize as atividades dos administradores.

Em um cenário como esse, a remuneração dos administradores se torna um mecanismo bastante propício para abusos. A assimetria de informação entre acionistas e administradores, somada à dificuldade de monitoramento das atividades dos administradores e à ausência de incentivos individuais para a fiscalização, podem representar um terreno fértil para a adoção de comportamentos oportunistas dos administradores, consistentes, por exemplo, na elevação injustificada de sua remuneração.

Recentes estudos empíricos sobre dados das companhias brasileiras demonstram a existência de uma associação direta entre a dispersão da propriedade acionária e o aumento da remuneração dos administradores das companhias abertas. ${ }^{6}$ Se a tendência de aumento da dispersão acionária efetivamente se concretizar, esse será mais um fator que fará da fiscalização da remuneração dos administradores um desafio importante a ser enfrentado pelos investidores brasileiros nos próximos anos.

\subsection{Plano da exposição e divisão do trabalho}

O estudo encontra-se dividido em seis capítulos: (i) introdução; (ii) sociedade anônima, alinhamento de interesses e remuneração dos administradores; (iii) remuneração dos administradores das sociedades anônimas na Lei $\mathrm{n}^{\circ}$ 6.404, de 1976; (iv) participação nos lucros; (v) remuneração dos administradores baseada em ações; e (vi) considerações finais.

\footnotetext{
${ }^{6}$ Cf. M. B. PINTO, Relação entre dispersão acionária e remuneração dos administradores de companhias abertas brasileiras, Dissertação de Mestrado apresentada na Escola de Pós Graduação em Economia da Fundação Getulio Vargas, Rio de Janeiro, 2011.
} 
Neste capítulo 1, procurou-se apresentar o tema, seus sentidos e limites. Procurouse, ainda, destacar que, não obstante a sempre existente preocupação com o estudo da remuneração dos administradores, três razões atuais intensificam a importância da análise sobre os incentivos outorgados aos administradores das companhias: (i) a recente edição da Instrução CVM n 480, de 2009, que instaurou novos padrões de transparência para as companhias abertas, notadamente sobre informações relativas à remuneração de seus administradores; (ii) o crescimento do mercado de capitais brasileiro na última década; e (iii) a transformação da estrutura de propriedade de algumas companhias brasileiras, que têm presenciado uma crescente dispersão da propriedade acionária.

O capítulo 2 apresenta um panorama da discussão sobre o tema nos Estados Unidos, país exportador de modelos e estruturas de remuneração dos administradores. Para tanto, o capítulo faz uma incursão na recente evolução da disciplina legal e regulamentar da remuneração dos administradores naquele país, com o intuito de extrair contribuições para o aprimoramento das discussões teóricas e práticas sobre o assunto no Brasil. O capítulo incursiona também na discussão teórica dos possíveis problemas e custos oriundos da delegação da administração da companhia e da segregação entre a propriedade acionária e o controle societário, os chamados custos de agência. Particularmente, serão analisados os diferentes enfoques que a literatura teórica, sobretudo a americana, tem conferido à remuneração dos administradores: solução para os problemas de agência ou parte integrante deles. Apresenta-se, ainda, um ponto de vista conciliatório desses dois enfoques. Seguindo a tendência de aumento da dispersão acionária no Brasil, serão analisadas, na sequência, as associações entre a dispersão da propriedade acionária e a remuneração dos administradores, à luz de recentes estudos empíricos sobre o assunto realizados com dados de companhias brasileiras.

O capítulo 3 analisará a legislação e regulamentação societárias referentes à remuneração dos administradores no Brasil. O capítulo procura discutir o conceito de remuneração utilizado na Lei $n^{\circ}$ 6.404, de 1976, bem como sua natureza, alicerces sobre os quais se estruturará o trabalho subsequente. Esse capítulo cuida, ainda, do contexto histórico em que se inserem, ao longo do tempo, os dispositivos legais referentes à remuneração dos administradores e de como esse contexto se relaciona com a evolução da concepção de "interesse social". Analisa-se de modo mais concreto o caput do art. 152 da 
Lei $n^{\circ}$ 6.404, de 1976, os tipos de remuneração, a competência, o procedimento e os parâmetros para fixá-la, bem como questões práticas como a acumulação de remunerações, a renúncia ou destituição do administrador de seu cargo, a remuneração dos membros do conselho fiscal e a remuneração dos administradores nos grupos societários. Também são analisados nesse capítulo o comitê de remuneração e o seu funcionamento, e os eventuais benefícios outorgados ao administrador em virtude de seu desligamento (golden parachutes). Por fim, o capítulo objetiva analisar os dispositivos da Instrução CVM no 480, de 2009, referentes à remuneração dos administradores, discutindo aspectos como exigência de transparência imposta pela referida norma.

A participação nos lucros e a remuneração baseada em ações também integram a remuneração dos administradores. Entretanto, em vista de sua importância para as companhias brasileiras, bem como da existência de dispositivos da Lei nº 6.404, de 1976, que tratam especificamente dessas modalidades remuneratórias, a participação nos lucros e a remuneração baseada em ações serão tratadas em capítulos autônomos.

No capítulo 4, será analisado o instituto da participação nos lucros. Serão objeto de estudo o conceito e a natureza da participação nos lucros. Sob uma perspectiva jurídicoeconômica, o capítulo procura discutir a percepção de risco pelos administradores e o free rider problem, presentes quando se adota uma estrutura remuneratória baseada no compartilhamento dos resultados. De maneira mais concreta, serão analisados os seguintes dispositivos da Lei $n^{\circ}$ 6.404, de 1976: (i) o art.152, $\S 1^{\circ}$ e $2^{\circ}$, os limites impostos à participação nos lucros, os diferentes entendimentos teóricos sobre tais limites e sobre a existência de participações estatutárias e extra estatutárias; (ii) o art. 189 e o art. 190, e a base para cálculo da participação nos lucros; e (iii) o art. 201, e a responsabilidade dos administradores. Em seguida, discutem-se questões práticas como a participação com base em lucros intermediários; destituição de administrador e participação nos lucros; o regime diferenciado das companhias com até vinte acionistas (art. 294, da Lei no 6.404, de 1976); e a participação nos lucros nos grupos societários. Por fim, o capítulo analisa e discute os dispositivos da Instrução CVM nº 480, de 2009, aplicáveis à participação nos lucros.

O capítulo 5 cuidará da remuneração dos administradores baseada em ações, particularmente da opção de compra de ações. À luz do art. $168, \S 3^{\circ}$, da Lei no 6.404 , de 
1976, serão analisados o conceito, o funcionamento e os requisitos para a implementação de planos de opções de compra de ações. O capítulo tratará também dos meios que a companhias geralmente utilizam para compor o conjunto de ações com as quais remunerarão os administradores mediante a outorga de opções de compra, bem como da exclusão do direito de preferência, nos termos do art. 171, § $3^{\circ}$, da Lei no 6.404, de 1976. Serão analisadas, ainda, outras modalidades de remuneração baseada em ações, como os planos de ações restritas e as phantom stock options. O capítulo discute aspectos recente Resolução CMN no 3.921, de 2010, que trata da remuneração dos administradores de instituições financeiras. Ao final, o capítulo se dedica a discutir eventuais comportamentos oportunísticos dos administradores relacionados à remuneração baseada em ações e os itens da Instrução CVM nº 480, de 2009, aplicáveis a esse tipo de remuneração.

Finalmente, o capítulo 6 consubstancia as considerações finais da dissertação. Nele serão retomadas as principais ideias desenvolvidas ao longo do estudo e sintetizadas as conclusões obtidas, destacando-se também as reflexões e os estudos ainda por serem realizados para o aprimoramento das discussões teóricas e práticas sobre a remuneração dos administradores das sociedades anônimas. 


\section{CONSIDERAÇÕES FINAIS}

O presente estudo teve por objetivo analisar a disciplina jurídica da remuneração dos administradores de sociedades anônimas a partir de três perspectivas, quais sejam: (i) a dos incentivos que as estruturas de remuneração podem gerar ao desempenho dos administradores; (ii) a dos problemas e conflitos que a remuneração pode causar, notadamente entre os acionistas controladores e os não controladores, bem como entre os administradores e os acionistas; e (iii) a das soluções que a remuneração proporciona, sobretudo ao alinhar os interesses dos administradores com os da companhia e dos acionistas.

Como o trabalho procurou demonstrar, o momento atual é oportuno para se refletir analiticamente sobre as estruturas e a disciplina legal da remuneração dos administradores por três razões recentes e fundamentais: (i) a edição da Instrução CVM no 480, de 2009, que instaurou um novo padrão de exigências de transparência para as companhias brasileiras; (ii) o crescimento do mercado de capitais brasileiro na última década; e (iii) a dispersão da propriedade acionária já observada em algumas companhias, bem como a relação que essa dispersão trava com a remuneração dos administradores.

Diante dessa conjuntura, o capítulo 2 procurou conferir ao trabalho um panorama da discussão sobre a remuneração dos administradores nos Estados Unidos, vanguarda indisputável nas tendências remuneratórias. O capítulo parte do pressuposto de que "custos de agência" e "conflitos de interesse", embora sejam problemas enfrentados em realidades econômicas subjacentes bastante diferentes, podem ter uma raiz comum, que consiste no descontrole de poder (dos administradores, onde a propriedade acionária é dispersa, e dos controladores, onde ela é concentrada).

Partindo-se desse pressuposto, a experiência prática norte-americana que já é rica pode se tornar particularmente útil, daí a importância de analisar as tendências regulatórias naquele país. Tais tendências mostram que iniciativas governamentais adotadas no mercado americano, por mais de uma vez, geraram efeitos indesejados - para não dizer opostos aos almejados - pelos reguladores. Foi assim com a tentativa de limitar a 
remuneração dedutível para fins de imposto de renda e com a tentativa de limitar o valor das cláusulas de golden parachutes.

Mas além das possíveis raízes coincidentes que os "problemas de agência" e os "conflitos de interesse" podem ter, a análise da experiência americana se mostra importante também pelo momento de transição com que o mercado brasileiro convive. Se a tendência de aumento da dispersão se confirmar, é possível que os investidores enfrentem desafios novos.

É possível que eles tenham que lidar, além do poder do controlador, também com o poder dos administradores, cuja influência nos processos de fixação de remuneração pode agravar os problemas de agência. Aliás, há estudos empíricos recentes demonstrando uma possível associação positiva entre aumento da dispersão acionária e incremento da remuneração dos administradores.

Nesse cenário de possíveis mudanças de desafios, ou mesmo de manutenção dos desafios atuais, mas de crescimento do mercado, rediscutir a disciplina jurídica da remuneração dos administradores pode ser bastante relevante. Para tanto, além de discutir as técnicas, os procedimentos, as formalidades e os requisitos estabelecidos pela Lei $\mathrm{n}^{\circ}$ 6.404, de 1976, o presente trabalho procurou agregar dois componentes que tem se mostrado como tendências importantes.

O primeiro deles é a transparência das informações relativas à remuneração dos administradores. Como o trabalho procurou demonstrar, a transparência pode funcionar como um efetivo e natural mitigador da assimetria informacional entre, de um lado, controladores e administradores, e, de outro, os acionistas, aumentando a capacidade de monitoramento por parte desses últimos. Mas, mais do que isso. $\mathrm{O}$ estudo procura demonstrar que a transparência também pode desencadear um efeito indutor de comportamentos lícitos e adequados, e que, portanto, alinhem os interesses dos administradores, da companhia e dos acionistas.

O segundo componente é a independência. Em qualquer dos cenários - seja de propriedade acionária dispersa, seja de controle concentrado - a independência é elemento 
essencial, pois veicula soluções tanto para os problemas de agência quanto para os conflitos de interesse. Por essas razões, o trabalho procurou focar atenção no comitê de remuneração, como elemento agregador de independência e redutor dos conflitos entre controladores e administradores de um lado, e acionistas de outro.

Esses componentes talvez não sejam suficientes; mas certamente serão necessários para que os investidores encarem esse possível novo desafio que à frente deles se coloca.

Os capítulos 4 e 5 procuraram rediscutir duas das modalidades remuneratórias histórica e quantitativamente mais utilizadas pelas companhias brasileiras: a participação nos lucros e a remuneração baseada em ações.

No capítulo 4, foram discutidas questões formais como conceituação, natureza, e requisitos das participações nos lucros. Para cumprir esse objetivo, analisou-se pormenorizadamente a disciplina legal da participação nos lucros, sobretudo à luz das seguintes questões: (i) o art. 152, $\S \S 1^{\circ}$ e $2^{\circ}$, os limites impostos à participação nos lucros, os diferentes entendimentos teóricos sobre tais limites e sobre a existência de participações estatutárias e extra estatutárias; (ii) o art. 189 e o art. 190, e a base para cálculo da participação nos lucros; (iii) o art. 201, e a responsabilidade dos administradores; e (iv) a participação nos grupos societários. Em seguida, discutiram-se questões práticas como a participação com base em lucros intermediários; destituição de administrador e participação nos lucros; e o regime diferenciado das companhias com até vinte acionistas (art. 294, da Lei n 6.404, de 1976).

O capítulo 5 cuidou dos problemas relativos à remuneração baseada em ações, especialmente as opções de compra de ações, enfatizando (i) o conceito, o funcionamento e os requisitos para a implementação de planos de opções de compra de ações; (ii) os meios que a companhias geralmente utilizam para compor o conjunto de ações com as quais remunerarão os administradores mediante a outorga de opções de compra; (iii) a exclusão do direito de preferência, nos termos do art. 171, $\S 3^{\circ}$, da Lei $n^{\circ}$ 6.404, de 1976. Também foram analisadas outras modalidades de remuneração baseada em ações, como os planos de ações restritas e as phantom stock options. O capítulo discutiu ainda aspectos da recente 
Resolução CMN n 3.921, de 2010, que trata da remuneração dos administradores de instituições financeiras.

Mas ambos os capítulos também conferiram ênfase às exigências de transparência impostas às companhias no que diz respeito à participação nos lucros e à remuneração baseada em ações. Com a exigência de divulgação das métricas utilizadas e o seu acesso pelo regulador e pelos acionistas, há uma tendências de que as modelagens adotadas sejam claras e precisas, de modo que os estímulos ao alinhamento de interesses sejam perceptíveis pelos destinatários das informações e, com isso, .mitiguem-se os incentivos perversos e comportamentos oportunísticos.

Considerando os três pontos de partida do presente trabalho, quais sejam: (i) a edição da Instrução CVM no 480, de 2009, que instaurou um novo padrão de exigências de transparência para as companhias brasileiras; (ii) o crescimento do mercado de capitais brasileiro na última década; e (iii) a dispersão da propriedade acionária já observada em algumas companhias, bem como a relação que essa dispersão trava com a remuneração dos administradores, os próximos anos serão de fundamental importância no aprimoramento das discussões teóricas sobre o tema. 


\section{BIBLIOGRAFIA.}

ADAmEK, Marcelo Vieira von, Responsabilidade civil dos administradores de S.A. e as ações correlatas, São Paulo, Saraiva, 2009.

AgÊncia Brasileira de Desenvolvimento Industrial - ABDI, A indústria de Private Equity e Venture Capital $-2^{\circ}$ Censo Brasileiro, março de 2011, disponível em www.abdi.com.br.

Agrawal, Anup, KnOEBer, Charles, Managerial compensation and the threat of takeover, in Journal of Financial Economics, v. 47, 1998, pp. 219/339.

AKERLOF, George, Labor contracts as partial gift exchange, in Quarterly Journal of Economics, vol. 97, 1982, pp. 543/569.

Alonso, Felix Ruiz, Dividendo e Participação de Diretoria, in RDM, n 23, 1976, pp. $167 / 174$.

Amaral, Paulo Afonso de Sampaio, S.A. Como era, como ficou após a Lei $n^{o}$ 9.457, de 5 5-1997, São Paulo, Editora Oliveira Mendes, 1998.

ANDRADE, Maria das Graças R. P. de, Parecer sobre participação de administradores nos lucros apurados em balanço semestral, in Revista da CVM, 1984, pp. 19/21.

AndRAde Filho, Edmar Oliveira, Imposto de Renda das Empresas, São Paulo, Atlas, 2009.

ARAgão, Paulo Cezar, Opções de Compra de Ações e Bônus de Subscrição, in RT, nº 631, 1988, pp. 63/70.

Aragão, Paulo Cezar, SoARES, Daniela, Opções de compra de ações: uma análise da evolução do instituto no Brasil, in CASTRO, Rodrigo R. Monteiro de, AzEvedo, Luís André N. de Moura (coord.), Poder de Controle e outros temas de direito societário e mercado de capitais, São Paulo, Quartier Latin, 2010, pp. 157/176.

AraúJo Cintra, Maria Lúcia, Sociedade comercial; anônima; assembleia geral; representação de acionistas (comentário a acórdão), in $R D M, \mathrm{n}^{\circ} 43,1981$, pp. 86/94. 
Armour, John, Hansmann, Henry, KraAkman, Reinier, Agency Problems and Legal Strategies, in R. KRAAKMAN, et. al., The Anatomy of corporate law - a comparative and functional approach, $2^{\text {nd }}$ edition, New York, Oxford University Press, 2009.

AsCARelli, Tullio, Problemas das sociedades anônimas e direito comparado, São Paulo, Saraiva, 1945.

Ascarelli, Tullio, O empresário, trad. port. de Fábio Konder Comparato, in RDM, $\mathrm{n}^{\circ}$ 109,1998, pp. 183/189.

ASQUINI, Alberto, I battelli del Reno, in Rivista delle società, 1959, p. 617.

BAKer, George P, Jensen, Michael C., MurPhy, Kevin J., Compensation and incentives: practive vs. theory, in The Journal of Finance, v. 43, 1987, pp. 593/616.

BARRETO FILHO, Oscar, Estrutura administrativa das sociedades anônimas, in Revista Forense, n $^{\circ} 258,1977$.

BArroso, Luís Roberto, CVM - invalidade do item 13.11 do Anexo 24 da Instrução CVM $n^{\circ}$ 480: legalidade e competências normativas - Privacidade e segurança individual, in Revista Semestral de Direito Empresarial, nº 6, 2010, pp. 297/334.

Bebchuk, Lucian A., FrIED, Jesse M., Pay without performance: the unfulfilled promise of executive compensation, Cambridge, Harvard University Press, 2004.

BeBCHUK, Lucian A., FRIED, Jesse M., Pay without performance: overview of the issues, in Journal of Applied Corporate Finance, v. 17, nº 4, 2005.

Bebchuk, Lucian A., FrIED, Jesse M., Executive compensation as an agency problem, 2003, disponível em http://papers.ssrn.com/abstract_id=364220.

Bebchuk, Lucian A., Fried, Jesse M., Stealth Compensation via Retirements Benefits, disponível em http://ssrn.com/abstract=583861, acesso em 03.11.2009.

Bebchuk, Lucian A., FrIEd, Jesse M., Executive Compensation at Fannie Mae: a Case Study of Perverse Incentives, Nonperformance Pay, and Camouflage, disponível em http://ssrn.com/abstract=653125.

Bebchuk, Lucian A., Fried, Jesse M., WALker, David I., Managerial Power and Rent Extraction in the Design of Executive Compensation, 2002, disponível em http://ssrn.com/abstract=316590. 
Bebchuk, Lucian A., Grinstein, Yaniv, The Growth of Executive Pay, disponível em http://ssrn.com/abstract=648682.

BEBCHUK, Lucian A., Roe, MARK J., A theory of path dependence in corporate ownership and governance, 1999, disponível em http://papers.ssrn.com/paper.taf?abstract_id=192414. Bebchuk, Lucian A., Grinstein, Yaniv, Firm Expansion and CEO Pay, disponível em http://ssrn.com/abstract=838245.

Bebchuk, Lucian Arye, Gristein, Yaniv, PeYer, Urs, Lucky CEOs and Lucky Directors, in Journal of Finance, 2010, disponível em http://papers.ssrn.com/abstract_id=1673294.

Bebchuk, Lucian A., Cohen, Alma, Wang, Charles C. Y., Golden parachutes and the wealth of shareholders, 2012, disponível em www.ssrn.com/abstract=1718488.

BEBCHuk, Lucian Arye, Executive pay and the financial crisis, in The Harvard Law School Forum on Corporate Governance and Financial Regulation, fevereiro de 2012, disponível em http://blogs.law.harvard.edu/corpgov/2012/02/01/executive-pay-and-thefinancial-crisis/.

BeBCHuK, Lucian Arye, How to fix bankers' pay, 2010, disponível em http://ssrn.com/abstract=1673250.

Berle, Adolf C., MeAns, Gardner C., The modern corporation and private property, New Brunswick, Transaction Publishers, 1991.

Bhagat, Sanjai, Romano, Roberta, Reforming Executive compensation: simplicity, transparency and commiting to the long term, 2009, disponível em www.ssrn.com/abstract=1506742.

BLACK, Bernard S., The legal and institutional preconditions for strong securities markets, in UCLA Law Review, v. 48, 2001, pp. 781 e ss.

BoITEux, Fernando Netto, Responsabilidade civil do acionista controlador e da sociedade controladora, Rio de Janeiro, Forense, 1988.

Bulgarelli, Waldirio, Comentários à Lei das Sociedades Anônimas, São Paulo, Saraiva, 1978.

Bulgarelli, Waldirio, A proteção às minorias na sociedade anônima, São Paulo, Pioneira, 1977. 
Bulgarelli, Waldirio, Regime jurídico do conselho fiscal das S.A., Rio de Janeiro, Renovar, 1998.

BULgarelli, Waldirio, O conselho fiscal nas companhias abertas, São Paulo, RT, 1988.

Bulgarelli, Waldirio, Regime Jurídico da proteção às minorias nas S/A, Rio de Janeiro, Renovar, 1998.

Bulgarelli, Waldirio (coord.), Reforma da lei das sociedades anônimas, São Paulo, Pioneira, 1998.

Bulgarelli, Waldirio, Apontamentos sobre a responsabilidade dos administradores das companhias, in $R D M, \mathrm{n}^{\circ} 50,1983$, pp. 75/105.

Bulgarelli, Waldirio, Direito de fiscalização da companhia por acionista e dever de informar da administração, in $R T, \mathrm{n}^{\circ} 580,1984$, pp. 58/67.

BulhõEs, Octavio Gouvêa de, Considerações sobre o Financiamento das Empresas, in Revista Brasileira de Mercado de Capitais, v. 2, 1976, pp. 503 e ss.

Bulhões Pedreira, José Luiz, Finanças e demonstrações financeiras da companhia, Rio de Janeiro,Forense, 1989.

Bulhões Pedreira, José Luiz, Imposto de Renda - Pessoas Jurídicas, v. 1, Rio de Janeiro, Justec, 1979.

Burrough, Bryan, Helyar, John, Barbarians at the Gate: the fall of RJR Nabisco, New York, Collins Business Essentials, 2005.

CAlvo, Adriana, Diretor de sociedade anônima: patrão - empregado?, São Paulo, LTr, 2006.

CAlvo, Adriana, A natureza jurídica dos planos de opções de compra de ações no direito do trabalho ("employee stock option plans"), in Revista LTr, v. 69, n 09, 2005, pp. $1126 / 1130$

Campiglia, Américo Oswaldo, Comentários à Lei das Sociedades Anônimas, São Paulo, Saraiva, 1978.

CAMPos, Francisco, Direito comercial, Rio de Janeiro, Freitas Bastos, 1957.

CAmpos, Virgílio, Contrato de Trabalho do Diretor de Empresas, in RDM, $\mathrm{n}^{\mathrm{o}} 35,1979$, pp. 71 e ss.. 
Campos Batalha, Wilson de Souza, Comentários à Lei das Sociedades Anônimas, Rio de Janeiro, Forense, 1977.

Cantidiano, Luiz Leonardo, Direito societário e mercado de capitais, Rio de Janeiro, Renovar, 1994.

CAntidiano, Luiz Leonardo, Reforma da lei das S.A., Rio de Janeiro, Renovar, 2002.

CARMo, Eduardo de Sousa, Relações Jurídicas na Administração da S.A., Rio de Janeiro, Aide, 1988.

CARMO, Lie Uema do, Gargalos da governança: a remuneração dos administradores, artigo publicado no periódico Gazeta Mercantil, em 10 de janeiro de 2006.

CAROLI, Carla,O regime jurídico da divulgação de informações no mercado de capitais britânico, in Revista Semestral de Direito Empresarial, n.6, 2010, pp. 31/72.

Carvalho, Gil da Costa, Comentários aos arts. 138 a 160, in Vidigal, Geraldo de Camargo, MARTins, Ives Gandra da Silva (org.), Comentários à lei das sociedades por ações -lei 6.404/76, v. 4, São Paulo, Forense, 1999.

Carvalho, Eduardo de, Teoria e prática das sociedades por ações, São Paulo, José Bushatsky, 1960.

CARVAlho DE MendonçA, José Xavier, Tratado de direito comercial brasileiro, v. 1, 3 e

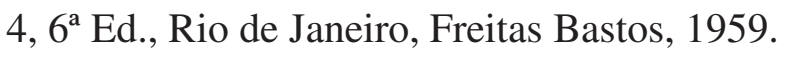

Carvalhosa, Modesto, Comentários à lei de sociedades anônimas, v. 1 a 4, $5^{\text {a }}$ ed., São Paulo, Saraiva, 2011.

Carvalhosa, Modesto e EIZIRIK, Nelson, Caráter intuitu personae da opção de compra de ações, in Estudos de Direito Empresarial, São Paulo, Saraiva, 2010, pp. 465/472.

Castello Branco, Adriano, O Conselho de Administração nas Sociedades Anônimas, $2^{\mathrm{a}}$ ed., Rio de Janeiro, Forense Universitária,2007.

CAStro, Rodrigo R. Monteiro de, Controle Gerencial, São Paulo, Quartier Latin, 2010.

Castro, Moema Augusta Soares de, SouZA, Carmen Godoy Vieira de, A obrigatoriedade da informação dos rendimentos dos administradores das companhias abertas sob o viés da análise econômica do direito: trade-off entre publicidade e privacidade e a eficiência da regulação, in WALD, Arnoldo et al. (coord.), Sociedades Anônimas e Mercado de Capitais, São Paulo, Quartier Latin, 2011, pp. 465/491. 
CATÃo, Marcos André Vinhas, Tributação de Stock Options, in Revista Dialética de Direito Tributário, no 127, 2006, pp. 57/67.

CEREZETTI, Sheila Christina Neder, Administradores independentes e independências dos administradores (regras societárias fundamentais ao estímulo do mercado de capitais brasileiro), in ADAMEK,Marcelo Vieira von (coord.), Temas de Direito Societário e Empresarial Contemporâneos, São Paulo, Malheiros, 2011.

Chediak, Julian Fonseca Peña, O conflito de interesses do administrador de sociedade anônima: uma sugestão de alteração no enfoque do tema, in ADAMEK, Marcelo Vieira von (coord.), Temas de Direito Societário e Empresarial Contemporâneos, São Paulo, Malheiros, 2011.

CheFFins, Brian R., ThOMAS, Randall S., Regulation and the globalization (Americanization) of executive pay, 2001, disponível em www.ssrn.com/abstract_id=321423.

CinTRA, Maria Lúcia de Araújo, Aspectos jurídicos de bônus de subscrição, Dissertação de Mestrado defendida na Faculdade de Direito da Universidade de São Paulo, 1980.

Clark, Robert Charles, Corporate Law, New York, Aspen Law \& Business, 1986.

CoElHo, Wilson do Egito, Da responsabilidade dos administradores das sociedades por ações em face da nova lei e da lei 6.024/74, in RDM, nº 40, 1980, pp. 37/49.

COFFEE JR., John C., What caused Enron?: A capsule social and economic history of the 1990’s, 2003, disponível em http://ssrn.com/abstract_id=373581.

Comparato, Fábio Konder, Ensaios e pareceres de direito empresarial, Rio de Janeiro, Forense, 1978.

Comparato, Fábio Konder, Novos ensaios e pareceres de direito empresarial, Rio de Janeiro, Forense, 1981.

Comparato, Fábio Konder, Direito empresarial: estudos e pareceres, São Paulo, Saraiva, 1995.

COMPARATO, Fábio Konder, Reflexões sobre as promessas de cessão de controle societário, in Novos Ensaios e Pareceres de Direito Empresarial, Rio de Janeiro,Forense, 1981, pp. 228/244. 
Comparato, Fábio Konder, $O$ direito de subscrição em aumento de capital, no fideicomisso acionário, in RDM, n 40, 1980, pp. 63/78.

Comparato, Fábio Konder, Exegese legal do requisito da residência no Brasil dos administradores de sociedade anônima, in RDM, n 44,1981, pp. 76/88.

Comparato, Fábio Konder, Estado, empresa e função social, in $R T$, no 732, 1996, pp. $38 / 46$.

COMPARATO, Fábio Konder, A constituição da reserva de lucros a realizar e o dividendo mínimo obrigatório, in Novos ensaios e pareceres de direito empresarial, Rio de Janeiro, Forense, 1981, pp. 146 e ss.

COMPARATO, Fábio Konder, A reforma da empresa, in $R D M, \mathrm{n}^{\circ}$ 50, 1983, pp. 57 e ss..

Comparato, Fábio Konder, Aspectos jurídicos da macro-empresa, São Paulo, RT, 1970.

COMPARATO, Fábio Konder, Comentários às disposições transitórias da nova lei de sociedades por ações, Rio de Janeiro, Forense, 1978.

Comparato, Fábio Konder, Funções e Disfunções do Resgate Acionário, in Direito empresarial: estudos e pareceres, São Paulo, Saraiva, 1990.

COMPARATO, Fábio Konder, Competência privativa do conselho de administração para a designação de diretores, em companhia aberta, in Novos Ensaios e Pareceres de direito empresarial, Rio de Janeiro, Forense, 1981, pp. 88 e ss.

Comparato, Fábio Konder, Lucros Sociais, Participações e Dividendo, in Novos Ensaios e Pareceres de Direito Empresarial, Rio de Janeiro, Forense, 1981, pp. 148/164.

Comparato, Fábio Konder, Comentários às Disposições Transitórias da Nova Lei das Sociedades Anônimas, Rio de Janeiro, Forense, 1978.

Comparato, Fábio Konder, $O$ poder de controle na sociedade anônima, $3^{\mathrm{a}}$ ed., Rio de Janeiro, Forense, 1983.

Conyon, Martin J., Fernandes, Nuno, Ferreira, Miguel A., Matos, Pedro, Murphy, Kevin J., The executive compensation controversy: a transatlantic analysis, 2011, disponível em http://digitalcommons.ilr.cornell.edu/cgi/viewcontent.cgi?article=1004\&context=ics.

Conyon, Martin J., Freeman, Richard B., Shared Modes of Compensation and Firm Performance: UK Evidence, 2001, disponível em http://ssrn.com/abstract=281079. 
CORREIA, Luís Brito, Os administradores de sociedades anônimas, Coimbra, Almedina, 1993.

CORREIA, Luís Brito, VENTURA, Raul, Responsabilidade dos administradores de sociedades anônimas e dos gerentes das sociedades por quotas, Lisboa, 1970.

CRISTIANO, Romano, Órgãos da sociedade anônima, São Paulo, RT, 1982.

Cristiano, Romano, Características e Títulos da Sociedade Anônima, São Paulo, RT, 1981, pp. $137 / 140$.

CunHA, Rodrigo Ferraz Pimenta da, Estrutura de interesses nas sociedades anônimas: hierarquia e conflitos, São Paulo, Quartier Latin, 2007.

DaInes, Robert, NAIR, Vinay B., Kornhauser, Lewis, The good, the bad, and the lucky: CEO pay and skill, 2005, disponível em www.ssrn.com/abstract=622223.

DAVID, Parthiban, KOCHHAR, Rahul, LEVITAS, Edward, The effect of institutional investors on the level and mix of CEO compensation, in The Academy of Management Journal, v. 41, 1998, pp. 200/208.

DAVIES, Paul L., Gower and Davies' Principles of Modern Company Law, $7^{\text {th }}$ ed., London, Sweet \& Maxwell, 2003.

DIAS, Luciana Pires, Regulação e auto-regulação no mercado de valores mobiliários, Dissertação de Mestrado defendida na Faculdade de Direito da Universidade de São Paulo, 2005.

EASTERBRoOK, Frank H., FISCHEl, Daniel R., The economic structure of corporate law, Cambridge, Harvard University Press, 1991.

EISENBERG, Melvin Aron, Corporations and other business organizations: cases and materials, $9^{\text {th }}$ Ed., New York, Foundation Press, 2005.

Eizirik, Nelson, GaAl, Ariádna B., PArente, Flávia, Henriques, Marcus de Freitas, Mercado de Capitais - regime jurídico, $2^{\mathrm{a}}$ ed., Rio de Janeiro, Renovar, 2008.

EIZIRIK, Nelson, Conselho fiscal, in LOBO, Jorge (org.), Reforma da lei das sociedades anônimas, Rio de Janeiro, Forense, 2003, pp. 453 e ss..

EIZIRIK, Nelson,Insider trading e responsabilidade de administrador de companhia aberta, in Questões de direito societário e mercado de capitais, Rio de Janeiro,Forense, 1987. 
EIZIRIK, Nelson,Responsabilidade civil e administrativa do diretor de companhia aberta, in Questões de direito societário e mercado de capitais, Rio de Janeiro,Forense, 1987.

EIZIRIK, Nelson, Reforma das S.A. e do mercado de capitais, Rio de Janeiro,Renovar, 1997.

EIZIRIK, Nelson, Bônus de Subscrição. Cláusula de ajustamento do preço de exercício. Aplicação em decorrência de aumento de capital efetuado para atender a plano de opção de compra de ações, in Temas de Direito Societário, Rio de Janeiro,Renovar, 2005, pp. $449 / 474$.

Eizirik, Nelson, Carvalhosa, Modesto, A nova lei das S/A, São Paulo,Saraiva, 2002.

EnRiQues, Luca, Hansmann, Henry, KraAKman, Reinier, The Basic Governance Structure, in R. KRAAKMAN, et. al., The Anatomy of corporate law - a comparative and functional approach, $2^{\text {nd }}$ edition, New York, Oxford University Press, 2009.

EnRiQues, Luca Hertig, Gerard, KANDA, Hideki, Related-Party Transactions, in R. KRAAKMAN, et. al., The Anatomy of corporate law - a comparative and functional approach, $2^{\text {nd }}$ edition, New York, Oxford University Press, 2009.

EUROPEAN COMISSION, Green Paper, The EU corporate governance framework, Brussels, 2011, disponível em http://europa.eu/documentation/official-docs/greenpapers/index_en.htm.

Ferrarini, Guido, Moloney, Niamh, Executive Remuneration in the EU: the context for reform, 2005, disponível em www.ssrn.com/abstract=715862.

FERREIRA, Waldemar, Tratado de direito comercial, v. 1 e 4 a 7, São Paulo, Saraiva, 1961. FERREIRA, Waldemar, Instituições de direito comercial, $2^{\mathrm{a}}$ ed., Rio de Janeiro, Freitas Bastos, 1947.

FERREIRA, Waldemar, Abuso de direito das assembleias gerais no fixarem os subsídios dos diretores das sociedades anônimas, in Revista de Direito Mercantil, v. II, 1952, pp. $528 / 553$.

Forgioni, Paula A., Messina, Paulo de Lorenzo, Sociedade por ações: jurisprudência, casos e comentários, São Paulo, RT, 1999.

FrANÇA, Erasmo Valladão Azevedo e Novaes, Conflito de interesses: formal ou substancial? Nova decisão da CVM sobre a questão, in RDM, $\mathrm{n}^{\circ} 128,2002$, pp. 225 e ss.. 
FRANÇA, Erasmo Valladão Azevedo e Novaes, Conflito de interesses nas assembleias de S.A., São Paulo, Malheiros, 1993.

FRANÇA, Erasmo Valladão Azevedo e Novaes, Invalidade das deliberações de assembleias das S.A., São Paulo, Malheiros, 1999.

FrAnÇA, Erasmo Valladão Azevedo e Novaes, Invalidade de deliberações conexas, in $R D M, \mathrm{n}^{\circ} 145,2007$, pp. 205 e ss.

FrANÇA, Erasmo Valladão Azevedo e Novaes, Apontamentos sobre a invalidade das deliberações conexas das companhias, in RDM, $\mathrm{n}^{\circ} 112,1998$, pp. 19/35.

Frydman, Carola, Jenter, Dirk, CEO Compensation, 2010, disponível em http://www.nber.org/papers/w16585.pdf?new_window=1.

Funchal, Jeférson de Araújo, TerRA, Paulo Renato Soares, Executive compensation, firm performance, and corporate governance in Latin America, artigo apresentado ao VII Encontro Brasileiro de Finanças, 2007, disponível em http://bibliotecadigital.fgv.br/ocs/index.php/ebf/7EBF/paper/viewFile/1827/937.

Galdi, Fernando Caio, CARVAlHo, L. Nelson, Remuneração em opções de ações: o SFAS 123 revisado, in Revista de Contabilidade e Finanças da Universidade de São Paulo, setembro de 2006, pp. 23/35.

Gervais, Simon, Heaton, J. B., OdeAn, Terrance, Overconfidence, Investment Policy and Executive Stock Options, Rodney L. White Center for Financial Research Working Paper $\mathrm{n}^{\circ}$ 15-02, também em http://papers.ssrn.com/sol3/papers.cfm?abstract_id=361200, acesso em 14 de março de 2011.

GeVurtz, Franklin A., Disney in a comparative light, 2007, disponível em www.ssrn.com/abstract $=965596$.

GOMES, Orlando, Responsabilidade dos administradores de sociedades por ações, in $R D M, \mathrm{n}^{\circ} 8,1972$, pp. 11 e ss..

Gomes, Orlando, VArela, Antunes, Direito Econômico, São Paulo, Saraiva, 1977.

Gonçalves, Almir Rogério, O Sistema Cambial Brasileiro e a Implantação de Programas de Stock Option, in $R D M, \mathrm{n}^{\circ} 119,2000$, pp. 142/154. 
GoRDON, Jeffrey N., Executive compensation: if there's a problem, what's the remedy? The case for "compensation discussion and analysis", 2006, disponível em www.ssrn.com/abstract $=686464$.

GORGA, Érica, Changing the paradigm of stock ownership from concentrated towards dispersed ownership? Evidence from Brazil and consequences for emerging countries, 2009, disponível em http://ssrn.com/abstract=1121037.

GreEnSPAn, Alan, Stock Options and related matters, in Revista de Direito Bancário, do Mercado de Capitais e da Arbitragem, n 17, 2002, pp. 13/16.

Guerreiro, José Alexandre Tavares, $O$ Conselho Fiscal e o direito à informação, in $R D M, \mathrm{n}^{\circ} 45,1982$, pp. 29 e ss..

GuERreiro, José Alexandre Tavares, Regime jurídico do capital autorizado, São Paulo, Saraiva, 1984.

GuERREIRO, José Alexandre Tavares, Sociedade anônima: poder e dominação, in $R D M, \mathrm{n}^{\circ}$ 53,1984, pp. 72 e ss..

GuERREIRO, José Alexandre Tavares, Responsabilidade dos administradores de sociedades anônimas, in RDM, nº 42, 1981, pp. 69 e ss..

GUERREIRO, José Alexandre Tavares, Sociedade comercial; anônima; assembleia geral; contas da administração; aprovação fraudulenta; nulidade (comentário a acórdão), in $R D M, \mathrm{n}^{\circ} 47,1982$, pp. 61/65.

GuERreIRo, José Alexandre Tavares, Direito das minorias na sociedade anônima, in $R D M, \mathrm{n}^{\circ} 63,1986$, pp. 106/111.

GuERREIRO, José Alexandre Tavares, Sobre a opção de compra de ações, in RDM, n 39, 1980, pp. 226/229.

Guimarães, Ruy Carneiro, Sociedade por Ações, v. 2 e v. 3, Rio de Janeiro, 1960.

HADDOCK, David D., MACEY, Jonathan R., Regulation on demand: a private interest model, with application to insider trading regulation, in Journal of Law and Economics, $\mathrm{v}$. 30, 1987, pp. $311 / 352$.

Hamilton, Robert W., The Law of Corporations, $5^{\text {th }}$ ed., West Group, 2000.

Hansmann, Henry, The ownership of enterprise, Cambridge, Harvard University Press, 2000. 
HenN, Harry G., Law of Corporations, West Publising, St. Paul, Minn., 1986, pp. 421/441. HERON, Randall A., LIE, Erik, Does backdating explain the stock price pattern around executive stock option grants?, 2006, disponível em http://ssrn.com/abstract=877889.

HILL, Jennifer G., Regulating executive remuneration: international developments in the post-escandal era, 2006, disponível em www.ssrn.com/abstract=922299.

HoPT, Klaus, trad. port. Erasmo Valladão A. e N. França e Mauro M. Ketzer, Deveres Legais e Conduta Ética de Membros do Conselho de Administração e de Profissionais, in $R D M, \mathrm{n}^{\circ} 144,2006$, pp. 107/119.

Iudícibus, Sérgio de, Martins, Elizeu, GelbCKe, Ernesto Rubens, Manual de contabilidade das sociedades por ações - aplicável às demais sociedades, $6^{\mathrm{a}}$ ed., São Paulo,Atlas, 2003.

Jensen, Michael C., MurPhy, Kevin J., CEO Incentives - It's not how much you pay, but how, in Harvard Business Review, may/jun., 1990.

JENSEN, Michael C., How stock options reward managers for destroying value and what to do about it, Negotiation, Organizations and Markets Research Paper $n^{\circ}$ 04-27, abril de 2001, disponível em www.ssrn.com/abstract=480401.

Jensen, Michael C., MurPhy, Kevin J., Performance Pay and Top Management Incentives, in Foundations of Organizational Strategy, Harvard University Press, 1998, também disponível em http://ssrn.com/abstract=94009, acesso em 14 de março de 2011.

Jensen, Michael C., Murphy, Kevin J., Remuneration: Where we've been, how we got here, what are the problems, and how to fix them, ECGI Finance Working Paper $n^{\circ} 44$, 2004, disponível em http://ssrn.com/abstract=561305.

Jensen, Michael C., MurPhy, Kevin J., Pay and top-management incentives, in Journal of Political Economy, v. 98, 1990, pp. 225/264.

Jensen, Michael C., Meckling, William, Theory of the firm: managerial behavior, agency costs and ownership structure, in Journal of Financial Economics, v. 3, 1976.

Jones, Derek C., KATO, Takao, Pliskin, Jeffrey, Profit sharing and gainsharing: a review of theory, incidence and effects, 1994, diponível em http://ssrn.com/abstract=101593.

KAPlan, Steven N., Executive compensation and corporate governance in the U.S.: perceptions, facts and challenges, 2012, disponível em www.ssrn.com/abstract=2134208. 
KRAAKMAN, Reiner, et. al., The Anatomy of corporate law - a comparative and functional approach, $2^{\text {nd }}$ edition, New York, Oxford University Press, 2009.

Kruse, Douglas, Freeman, Richard, Blasi, Joseph, Do workers gain by sharing? Employee outcomes under employee ownership, profit sharing, and broad-based stock options, 2008, disponível em http://ssrn.com/abstract=1231686.

KRUSE, Douglas, Does Profit Sharing Affect Productivity, 1993, disponível em $\underline{\text { http://ssrn.com/abstract }=375304}$

KUMAR, Praveen, SIVARAMAKRISHNAN, K., Who monitors the monitor? The effect of board independence on executive compensation and firm value, in The Review of Financial Studies, v. 21, 2008, pp. 1371/1401.

LAFFOnT, Jean-Jacques, MARTIMORT, David, The theory of incentives - the principalagent model, Princeton, Princeton University Press, 2002.

Lamy Filho, Alfredo, Bulhões Pedreira, José Luiz, A lei das S.A., Rio de Janeiro, Renovar, 1992.

LAmy Filho, Alfredo, Bulhões PedReIRA, José Luiz, A remuneração de Empregado Eleito para Integrar Órgão de Administração, in A lei das S.A., Rio de Janeiro, Renovar, 1992, pp. 394 e ss..

LAmy Filho, Alfredo, Bulhões PedReIRA, José Luiz, Remuneração do conselho consultivo com participação nos lucros, in A lei das S.A., Rio de Janeiro, Renovar, 1992, pp. 606 e ss..

Lamy Filho, Alfredo, Bulhões PedreIRA, José Luiz (coord.), Direito das Companhias, Rio de Janeiro, Forense, 2009.

LAMY FILHO, Alfredo, Emissão de bônus de subscrição - outorga de opções de compra distinções entre os dois institutos, in Temas de S.A., Rio de Janeiro, Renovar, 2007, pp. $375 / 380$.

LAUTENSCHLEGER JÚNIOR, Nilson, Os desafios propostos pela governança corporativa ao direito empresarial brasileiro: ensaio de uma reflexão crítica e comparada, São Paulo, Malheiros, 2005.

LaZZAReschi Neto, Alfredo Sérgio, Lei das Sociedades por Ações anotada, São Paulo, Saraiva, 2006. 
LEÃES, Luiz Gastão Paes de Barros, Mercado de capitais e insider trading, São Paulo, RT, 1982.

LEÃES, Luiz Gastão Paes de Barros, Comentários à lei das sociedades anônimas, v. 2, São Paulo, Saraiva, 1980.

LeÃes, Luiz Gastão Paes de Barros, Da remuneração dos membros dos Conselhos de Administração in Estudos e pareceres sobre sociedades anônimas, São Paulo, RT, 1989, pp. 179 e ss..

LeÃes, Luiz Gastão Paes de Barros, Dividendos mínimos cumulativos e participantes, in $R D M, \mathrm{n}^{\circ} 111,1998$, pp. 157 e ss..

LeÃes, Luiz Gastão Paes de Barros, Dividendo obrigatório e participação dos administradores nos lucros da companhia, in Estudos e pareceres sobre sociedades anônimas, São Paulo, RT, 1989, pp. 198 e ss..

LEÃES, Luiz Gastão Paes de Barros, Do direito do acionista ao dividendo, São Paulo, Obelisco, 1969.

LEÃES, Luiz Gastão Paes de Barros, Remuneração dos administradores, in Estudos e pareceres sobre sociedades anônimas, São Paulo, RT, 1989, pp. 144 e ss..

LeÃes, Luiz Gastão Paes de Barros, Sociedade por ações; atos praticados por seus diretores, em razão de administração; responsabilidade daquela e destes, solidariamente, se agiram com culpa ou contrariamente aos estatutos (comentário a acórdão), in $R D M, \mathrm{n}^{\circ}$ 2, 1971, pp. 74/82.

LEÃEs, Luiz Gastão Paes de Barros, A álea normal do contrato e o momento do exercício das opções, in Revista de Direito Bancário e do Mercado de Capitais, n 39, 2008, pp. $101 / 115$.

LEÃEs, Luiz Gastão Paes de Barros, Pactode Opção de Compra (Call) de Ações em Acordo de Acionistas, in Pareceres, v. 2, São Paulo,Singular, 2004, pp. 1131/1141.

Lebow, David, Sheiner, Louise, SlifMan, Larry, StARr-McCluer, Martha, Recent Trends in Compensation Practices, 1999, p. 6, disponível em http://ssrn.com/abstract=186131.

LeEch, Noyes, Frey, Alexander, CHOPER, Jesse, Morris, Robert, Cases and Materials on Corporations, Boston, Little Brown and Company, 1977, pp. 201/202. 
LoBO, Jorge (coord.), A Reforma da Lei das S.A., São Paulo, Atlas, 1998.

Lobo, Jorge, Substituição dos administradores das sociedades anônimas, in $R T, \mathrm{n}^{\circ} 603$, 1985, pp. 38/51.

LoBo, Grupo de Sociedades, in RT, nº 636, out. 1988, pp. 25 e ss.

Lobo XAVIER, Vasco da Gama, Anulação de deliberação social e deliberações conexas, Coimbra, Atlantida, 1976.

LODI, João Bosco, Conselho de Administração, São Paulo, Pioneira, 1988.

LoPes, Mauro Brandão, S.A.: Títulos e Contratos Novos, São Paulo, RT, 1978, pp. 86/87.

LuCena, José Waldecy, Das Sociedades Anônimas - Comentários à Lei, v. 1 e 2, Rio de Janeiro, Renovar, 2009.

MACEy, Jonathan R., Corporate Governance: Promises Kept, Promises Broken, Princeton, Princeton University Press, 2010.

MAgALHÃEs, Roberto Barcellos de, A nova lei das sociedades por ações comentada, V. II, Rio de Janeiro, Livraria Freitas Bastos, p. 705.

MARChI, Eduardo César Silveira, Guia de metodologia jurídica: teses, monografias e artigos, $2^{\mathrm{a}}$ ed., São Paulo, Saraiva, 2009.

Marcondes, Sylvio, Conflito de interesses entre a sociedade e seu administrador, in Problemas de direito mercantil, São Paulo, Max Limonad, 1970.

Marcondes, Sylvio, Questões de direito mercantil, São Paulo, Saraiva, 1977.

Marion, José Carlos, Contabilidade empresarial, 13ª ed., Atlas, São Paulo, 2007.

Marote, Carla Lobo Olim, Participação dos empregados no capital da empresa: opção de compra de ações, Dissertação de Mestrado defendida na Faculdade de Direito da Universidade de São Paulo, 2003.

Martins, Fran, Comentários à Lei das Sociedades Anônimas, Rio de Janeiro, Forense, 1978.

MARTINS, Fran, Direito societário: estudos e pareceres, Rio de Janeiro, Forense, 1984.

MARTINS, Fran, Novos estudos de direito societário (sociedades anônimas e sociedades por quotas), São Paulo, Saraiva, 1988.

MARTINS, Ives Gandra da Silva, Distribuição disfarçada de lucros, in RDP, n. 26, 1973. 
Martins, Sérgio Pinto, Natureza do stock options no direito do trabalho, in Repertório IOB de Jurisprudência,n. 16, agosto de 2001.

MEHRAN, Hamid, Executive compensation structure, ownership, and firm performance, in Journal of Financial Economics, v. 38, 1995, pp. 163/184.

Morelli, Denis, Os órgãos técnicos e consultivos das sociedades anônimas, Dissertação de Mestrado apresentada na Faculdade de Direito da Universidade de São Paulo, 2012.

Morgan, Angela, Poulsen, Annette, Wolf, Jack, The Evolution of Shareholder Voting for Executive Compensation Schemes, in 12 Journal of Corporate Finance, 2006, pp. $715 / 737$.

MunhOZ, Eduardo Secchi, Empresa contemporânea e direito societário - poder de controle e grupos de sociedades, São Paulo, Juarez de Oliveira, 2002.

Munhoz, Eduardo Secchi, Desafios do direito societário brasileiro na disciplina da companhia aberta: avaliação dos sistemas de controle diluído e concentrado, in CASTRO, Rodrigo R. Monteiro de, AragÃo, Leandro Santos de (coord.), Direito societário desafios atuais, São Paulo, Quartier Latin, 2009, pp. 119/155.

Munhoz, Eduardo Secchi, Robert, Bruno, A lei n. 11.638/07 e o cálculo do dividendo mínimo obrigatório, in WARDE JÚNIOR, Walfrido (coord.), Fusão, cisão, incorporação e temas correlatos, São Paulo, Quartier Latin, 2009.

MURPHY, Kevin J., Executive Compensation, 1998, disponível em http://ssrn.com/abstract=163914.

Murphy, Kevin J., Explaining Executive Compensation: Managerial Power vs. the Perceived Cost of Stock Options, in University of Chicago Law Review, V. 69, n. 3, 2002, pp. $847 / 869$.

MURPHY, Kevin J., Corporate performance and managerial remuneration - an empirical analysis, in Journal of Accounting and Economics, v. 7, 1985, pp. 11/42.

MURPHY, Kevin J., The politics of pay: a legislative history of executive compensation, 2011, disponível em http://ssrn.com/abstract=1916358.

MurPhy, Kevin J., SAndino, Tatiana, Executive Pay and "Independent" Compensation Consultants, 2009, disponível em http://ssrn.com/abstract=1148991. 
MüSSNICH, Francisco Antunes Maciel, A utilização desleal de informações privilegiadas insider trading - no Brasil e nos Estados Unidos, in RDM, n. 34, 1979, pp. 31/51.

MÜSSnich, Francisco Antunes Maciel, NAscimento, João Pedro Barroso do, Eleição em separado de membro do conselho de administração (exegese do art. 141, $\$ 5^{\circ}$, da Lei 6.404/76), in ADAmEK, Marcelo Vieira von (coord.), Temas de Direito Societário e Empresarial Contemporâneos, São Paulo, Malheiros, 2011.

NERILO, Lucíola Fabrete Lopes, Responsabilidade civil dos administradores nas sociedades por ações, Curitiba, Juruá, 2001.

NeVes, Vanessa Ramalhete Santos, Responsabilidade dos administradores de sociedades anônimas, Rio de Janeiro, Lumen Juris, 2002.

NunEs, Pedro Caetano, Responsabilidade civil dos administradores perante os acionistas, Coimbra, Almedina, 2001.

OLsON, Mancur, The logic of collective action - Public goods and the theory of groups, Cambridge, Harvard University Press, 1971.

OYER, Paul, Why do firms use incentives that have no incentive effects?, 2000, disponível em http://ssrn.com/abstract=237917.

Pacheco, José da Silva, Tratado de Direito Empresarial, Sociedades Anônimas e Valores Mobiliários, São Paulo, Saraiva, 1977.

PAES, Paulo Roberto Tavares, Responsabilidade dos administradores de sociedades, $2^{\mathrm{a}}$ ed., São Paulo, RT, 1997.

Palepu, Krishna, Healy, Paul M., The Fall of Enron, 2003, disponível em www.ssrn.com/abstract $=417840$.

PARENTE, Flávia, O dever de diligência dos administradores de sociedades anônimas, Rio de Janeiro, Renovar, 2005.

PAUlin, Luiz Alfredo, Administrador de fato nas sociedades por ações, in RDM, n. 130, 2003, pp. 102/118.

Penteado, Mauro Rodrigues, Aumentos de capital das sociedades anônimas, São Paulo, Saraiva, 1988.

Penteado, Mauro Rodrigues, Sociedades de economia mista, empresas públicas e estatais; inexistência de limites a remuneração de seus administradores e empregados em 
face da nova constituição, in Revista Trimestral de Jurisprudência dos Estados São Paulo, v.74, São Paulo, 1990, pp. 37/58.

Penteado, Mauro Rodrigues, As sociedades de economia mista e as empresas estatais perante a Constituição Federal de 1988, in RDM, n. 73,1989, pp. 5/21.

Penteado, Mauro Rodrigues, Sociedade anônima: acionista controlador (comentário a acórdão), in $R D M$, n. 83,1991, pp. 99/116.

Penteado, Mauro Rodrigues, Notas sobre a nomeação dos administradores nas sociedades anônimas, in $R T$, n. 553, 1981, pp. 58/67.

PERES, Antonio Galvão, A natureza jurídica dos planos de opção de compra de ações para altos funcionários, in Revista Amatra, 2001.

PINTO, Marcos Barbosa, Relação entre dispersão acionária e remuneração dos administradores de companhias abertas brasileiras, Dissertação de Mestrado apresentada na Escola de Pós Graduação em Economia da Fundação Getulio Vargas, Rio de Janeiro, 2011.

PIRES, Gudesteu, Manual das sociedades anônimas, Rio de Janeiro, Freitas Bastos, 1942.

PonTES, Aloysio Lopes, Sociedades anônimas, $3^{\text {a }}$ ed., Rio de Janeiro, Forense, 1954.

POnTES De Miranda, Francisco Cavalcanti, Tratado de direito privado, t. 5, $3^{\mathrm{a}}$ ed., RT, São Paulo, 1984.

PRADO, Viviane Muller, Grupos Societários: análise do modelo da Lei 6.404/76, in Revista Direito GV, v. 2, jun./dez. 2005, pp. 5 e ss.

PRADO, Viviane Muller, Conflito de interesses nos grupos societários, São Paulo, Quartier Latin, 2006.

PROENÇA, José Marcelo Martins, Insider trading: regime jurídico do uso de informações privilegiadas no mercado de capitais, São Paulo, Quartier Latin, 2005.

Ramos, Maria Elisabete Gomes, A responsabilidade de membros da administração, in Problemas do direito das sociedades, Coimbra, Almedina, 2002.

RATHENAU, Walter, Do sistema acionário: uma análise negocial, trad. LAUTENSCHLEGER JR., Nilson, in $R D M, \mathrm{n}^{\circ} 128$, out./dez., 2002, pp. 199 e ss.

Requião, Rubens, Curso de Direito Comercial, v. 2, $29^{a}$ Ed., São Paulo, Saraiva, 2012. 
Rezende, Cesar Vieira de, Participação dos Administradores nos Lucros e Dividendos Obrigatórios, in RDM, n. 27, 1978, pp. 27 e ss..

RiBEIRO, Renato Ventura, Dever de diligência dos administradores de sociedades, São Paulo, Quartier Latin, 2006.

Rizzo, Valdo Cestari de, AlmeidA, Marco La Rosa de, Do direito do acionista à informação em companhias abertas e fechadas, in ADAMEK, Marcelo Viera von (coord.), Temas de Direito Societário e Empresarial Contemporâneos, São Paulo, Malheiros, 2011.

RoBert, Bruno, Dividendo Mínimo Obrigatório nas S.A., Apuração, Declaração e Pagamento, São Paulo, Quartier Latin, 2011.

Robortella, Luiz Carlos Amorim, Plano de compra de ações (stock options) mantido por grupo multinacional e concedido a alto executivo, in Revista de Direito do Trabalho, n. 101, São Paulo, 2001.

RochA, João Luiz Coelho da, Administradores, conselheiros e prepostos das sociedades, Rio de Janeiro, Lumen Juris, 2005.

RochA, Tatiana Nogueira da, Fundos de investimento e o papel do administrador, São Paulo, Textonovo, 2003.

RoE, Mark J., Strong Managers, Weak Owners, Princeton, Princeton University Press, 1994.

RomAnO, Roberta, Foundations of Corporate Law, $2^{\text {nd }}$ ed., New York, Foundation Press, 2010.

Salomão Filho, Calixto, O novo direito societário, $4^{\mathrm{a}}$ ed., São Paulo, Malheiros, 2011.

SAlomão FILHo, Calixto, Sociedade anônima: interesse público e privado in $R D M, \mathrm{n}^{\circ}$ 127, 2002, pp. 7 e ss..

SAlomão Filho, Calixto, A sociedade unipessoal, São Paulo, Malheiros, 1995.

SAlomão FILho, Calixto, Conflito de interesses: a oportunidade perdida, in LoBO, Jorge (coord.), A reforma da Lei das Sociedades Anônimas, 2a ed., Rio de Janeiro, Forense, 2002. SAmpaio CAmpos, Luiz Antônio de, Algumas notas sobre a utilização do lucro do exercício em curso: dividendo e recompra, in ADAMEK, Marcelo Vieira von (coord.), Temas de Direito Societário e Empresarial Contemporâneos, São Paulo, Malheiros, 2011. 
Sampaio de Lacerda, J. C., Comentários à Lei das Sociedades Anônimas, São Paulo, Saraiva, 1978.

SANTERRE, Rexford E., Neun, Stephen P., Stock dispersion and executive compensation, in The Review of Economics and Statistics, v. 68, 1986, pp. 685/687.

SANTos, Aline de Menezes, Reflexões sobre a governança corporativa, in RDM, n. 130, 2003, pp. 180/206.

SCHOUERI, Luís Eduardo, Distribuição disfarçada de lucros, São Paulo, Dialética, 1996.

SILVA, Antônio Angarita, Remuneração de diretores nas sociedades anônimas, in Revista de Administração de Empresas, v. 1, nº 1, mai/ago, 1961, pp. 93/104.

SILVA, Luciana Aboim Machado Gonçalves da, Employee Stock Options, in Revista IOB Trabalhista e Previdenciária, n. 199, 2006, pp. 109/119.

SILVA, Alexandre Couto, Responsabilidade dos administradores de S/A - Business judgement rule, Rio de Janeiro, Elsevier, 2007.

SILVA, José Manoel da, Alienação e distribuição disfarçada de lucros, in RDM, n. 18, 1975.

SoUZA JR., Francisco Satiro, Regime jurídico das opções negociadas em bolsa de valores, Tese de Doutorado defendida na Faculdade de Direito da Universidade de São Paulo, 2002.

STUBER, Walter Douglas, As novas regras para divulgação e uso de informações sobre atos ou fatos relevantes relativos às companhias abertas brasileiras, in Revista de Direito Bancário e do Mercado de Capitais, n. 16, 2002, pp. 263/268.

STUBER, Walter Douglas, A negociação com opções por companhia aberta, in Revista de Direito Bancário e do Mercado de Capitais, n. 23, 2004, pp. 394/396.

SzTAJn, Rachel, Contrato de sociedade e formas societárias, São Paulo, Saraiva, 1989.

SzTAjn, Rachel, Mello Franco, Vera Helena de, Manual de direito comercial, São Paulo, RT, 2005.

SzTAJn, Rachel, Sobre a natureza jurídica das opções negociadas em bolsas, in RDM, n. 105, 1997, pp. 53/69.

Tavares Borba, José Edwaldo, Direito societário, 8ª ed., Rio de Janeiro, Renovar, 2003. 
Tavares Borba, José Edwaldo, Opção de compra de ações, in Temas de Direito Comercial, Rio de Janeiro, Renovar, 2007, pp. 83/98.

Tavares Borba, José Edwaldo, Lei $n^{o}$ 9.457/97, A Reforma da Lei das Sociedades Anônimas, Rio de Janeiro, Lumen Juris, 1998.

TeIXEIRA, Egberto Lacerda, Guerreiro, José Alexandre Tavares, Das sociedades anônimas no direito brasileiro, v. 1 e 2, São Paulo, José Bushatsky, 1979.

Thomas, Randall S., MARTIN, Kenneth J., The effect of shareholder proposals on executive compensation, in University of Cincinnati Law Review, v. 67, 1999, pp. 1021/1081.

Toledo, Paulo Fernandes Campos Salles de, O conselho de administração na sociedade anônima, 2ª ed., São Paulo, Atlas, 1999.

Toledo, Paulo Fernandes Campos Salles de, Modificações introduzidas na Lei das Sociedades por Ações quanto á disciplina da administração das companhias, in LOBО, Jorge (coord.), A reforma da Lei das Sociedades Anônimas, $2^{\text {a }}$ ed., Rio de Janeiro, Forense, 2002.

VAlverde, Trajano de Miranda, Sociedades por ações, v. 1 e 2, Rio de Janeiro, Forense, 1941.

VAMPRÉ, Spencer, Tratado elementar de direito comercial, Rio de Janeiro, F. Briguet \& Cia., 1922.

Verçosa, Haroldo Malheiros Duclerc, Curso de Direito Comercial, São Paulo, Malheiros, 2006.

Vivante, Cesare, Trattato di diritto commerciale, $5^{\text {a }}$ ed, Milão, Francesco Vallardi, 1929.

Von ADAmEK, Marcelo Vieira, Responsabilidade civil dos administradores de S.A. e as ações correlatas, São Paulo, Saraiva, 2009.

YAZBEK, Otavio, Regulação do Mercado Financeiro e de Capitais, Rio de Janeiro, Elsevier, 2007.

Yermack, David, Good Timing: CEO Stock Option Awards and Company News Announcements, 1996, NYU Working Paper nº FIN-96-041, também disponível em http://ssrn.com/abstract=1298306, acesso em 14 de março de 2011.

XAVIER, Alberto, Administradores de Sociedades, São Paulo, RT, 1979. 
WALD, Arnoldo, Da responsabilidade individual dos diretores de sociedades anônimas nos campos civil e penal, in Estudos e pareceres de Direito Comercial, São Paulo, RT, 1979.

WALD, Arnoldo, A sociedade de capital aberto e a informação do acionista, in Estudos e pareceres de Direito Comercial, São Paulo, RT, 1972, pp. 209 e ss..

WALD, Arnoldo, Sociedade anônima: do regime legal do conselho de administração e da liberdade de votos dos seus componentes, in RT, n. 630, 1988, pp. 9/19.

WALD, Arnoldo, A evolução do regime legal do conselho de administração, os acordos de acionistas e os impedimentos dos conselheiros decorrentes de conflitos de interesses, in Revista de Direito Bancário e do Mercado de Capitais, n. 99, pp. $105 / 120$.

WaLD, Arnoldo, Da responsabilidade dos membros do Conselho de Administração no regime da Lei 6.024/74, in $R D M$, n. 70, 1988, pp. 5/14.

WALD, Arnoldo, O governo das empresas, in Revista de Direito Bancário e do Mercado de Capitais, n. 15, 2002, pp. 53/78.

WALD, Arnoldo, Caracterização do grupo econômico de fato e suas consequências quanto à remuneração dos dirigentes de suas diversas sociedades componentes, in Revista de Direito Bancário e do Mercado de Capitais, n 25, jul. 2004, pp. 145 e ss.

WIEDEMANN, Herbert, Vínculos de lealdade e regra de substancialidade: uma comparação de sistemas, trad. port. de Otto Carlos Vieira Ritter von Adamek, in ADAMEK, Marcelo Vieira von, Temas de Direito Societário e Empresarial Contemporâneos, São Paulo, Malheiros, 2011.

ZAITZ, Daniela, Responsabilidade dos administradores de sociedades anônimas e por quotas de responsabilidade limitas, in $R T$, n. 740, 1997, pp. 11/52.

Williamson, Oliver E., WinTER, Sidney G. (org.), The nature of the firm - origins, evolution and development, Nova Iorque, Oxford University Press, 1991. 